\title{
ON GROUND SURFACE EXTRACTION USING FULL-WAVEFORM AIRBORNE LASER SCANNER FOR CIM
}

\author{
K. Nakano ${ }^{\mathrm{a}, \mathrm{b}} *$, H. Chikatsu ${ }^{\mathrm{b}}$ \\ ${ }^{\mathrm{a}}$ Research and Development Center, AERO ASAHI CORPORATION, \\ 3-1-1, Minamidai, Kawagoe, Saitama, 350-1165, Japan - kazuya-nakano@aeroasahi.co.jp \\ ${ }^{\mathrm{b}}$ Division of Architectural, Civil and Environmental Engineering, Tokyo Denki University, \\ Ishizaka, Hatoyama, Saitama, 350-0394, Japan - chikatsu@g.dendai.ac.jp
}

Commission V, WG V/4

KEY WORDS: Airborne laser scanner, Full-waveform data, Ground surface extraction, Evergreen broad-leaved trees, Virtual ground surface

\begin{abstract}
:
Satellite positioning systems such as GPS and GLONASS have created significant changes not only in terms of spatial information but also in the construction industry. It is possible to execute a suitable construction plan by using a computerized intelligent construction. Therefore, an accurate estimate of the amount of earthwork is important for operating heavy equipment, and measurement of ground surface with high accuracy is required. A full-waveform airborne laser scanner is expected to be capable of improving the accuracy of ground surface extraction for forested areas, in contrast to discrete airborne laser scanners, as technological innovation. For forested areas, fundamental studies for construction information management (CIM) were conducted to extract ground surface using full-waveform airborne laser scanners based on waveform information.
\end{abstract}

\section{INTRODUCTION}

Since the Great East Japan Earthquake Disaster, coastal residential areas have been shifting to higher elevations. However, there are no suitable places for relocation that is unaffected by tsunamis. Therefore, cutting and filling of earth must be performed in mountains for converting them to residential areas. In order to achieve planned construction in a section of a mountain, it is necessary to obtain accurate ground surface information before felling trees. Estimation of accurate soil volume is important for the planned work because it determines the cost and operating time of heavy equipment. However, it is difficult to accurately estimate soil volume because of the influence of dense vegetation in the mountain. Airborne laser scanners (ALS) have been widely used because of their effectiveness in extracting micro topography or ground surface in forested areas, which are not detected in photogrammetry, and many of its applications such as city modeling, DTM generation, electrical power line monitoring, and calculation of forest area volume have been proposed. The abilities of ALSs are significantly increasing through technological innovations. Many ALSs such as high-pulse-rate laser scanners and full-waveform ALSs were developed by improving the time resolution in pulse analyses. Full-waveform ALSs can extract waveform information to continuously record reflection information from one laser irradiation in a short time interval. Therefore, full-waveform ALSs are expected to be made capable of increasing the density and accuracy of point cloud of ground surface in forest areas in contrast to conventional discrete ALSs. However, it is considered that it would be very difficult to classify very weak reflection information. It would be difficult to separate noise passing through the gap between the trees from the laser irradiation reflected from the ground.
This paper describes a fundamental study on extracting ground surface from forested areas using a full-waveform ALS for construction information management (CIM).

\section{FULL-WAVEFORM AIRBORNE LASER SCANNER}

One of the features of the full-waveform ALS is that reflection information of laser can be continuously obtained as waveform. Figure 1 is a conceptual diagram showing the difference between conventional discrete airborne scanners and fullwaveform airborne scanners.

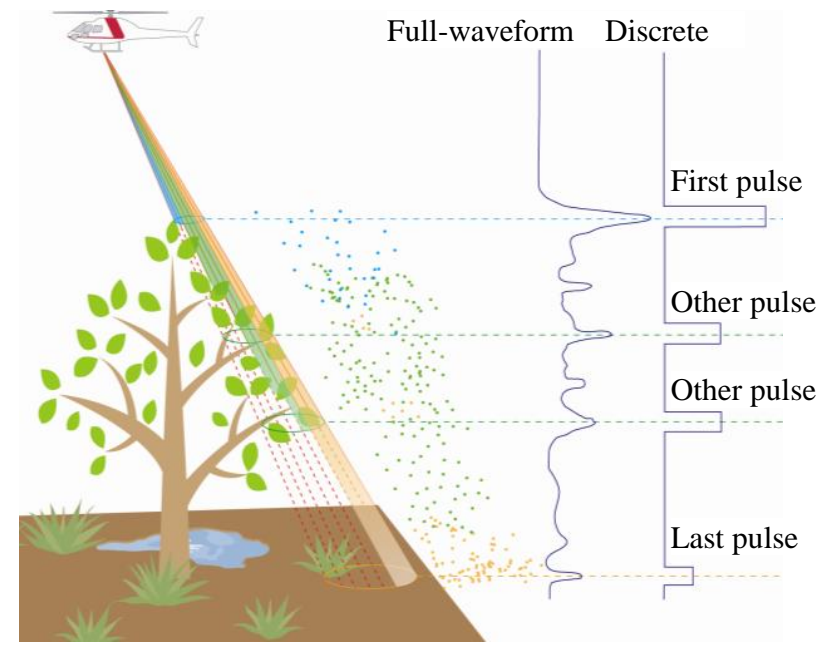

Figure 1. Airborne laser scanner conceptual diagram

\footnotetext{
* Corresponding author
} 
Conventional discrete ALSs obtain three-dimensional coordinates and reflection intensity of discrete pulses as shown in the Figure 1; the first reflection from the crown of a tree is taken as the first pulse, the last reflection from the ground surface is taken as the last pulse, and all reflections between them are taken as other pulses.

The application of output from conventional ALSs to our original algorithm is difficult for processing in the analysis software, which was provided by the ALS manufacturer. On the other hand, the full-waveform ALS can analyze weak reflections for continuously recording reflection information with very short time resolutions such as one nanosecond. It is also possible to compute new three-dimensional coordinates using the continuous reflection information.

\section{DATA ACQUISITION}

In order to confirm the ability of the full-waveform ALS to extract ground surface in forested areas, data acquisition was performed at the Institute for Nature Study, which is located at Shirokanedai, Minato-ku, Tokyo. The area has a variety of vegetation such as evergreen broad-leaved and deciduous trees. Table 1 shows data specifications used in this fundamental study. Figure 2 shows a simple ortho-image that was created using images taken by a digital camera mounted on the ALS in order to confirm the situation of the vegetation. Radiometric correction was not performed for the simple ortho-image for realistic visibility. Data was acquired on October 20, and it can be seen from Figure 2 that the vitality of most of the trees have not been significantly reduced.

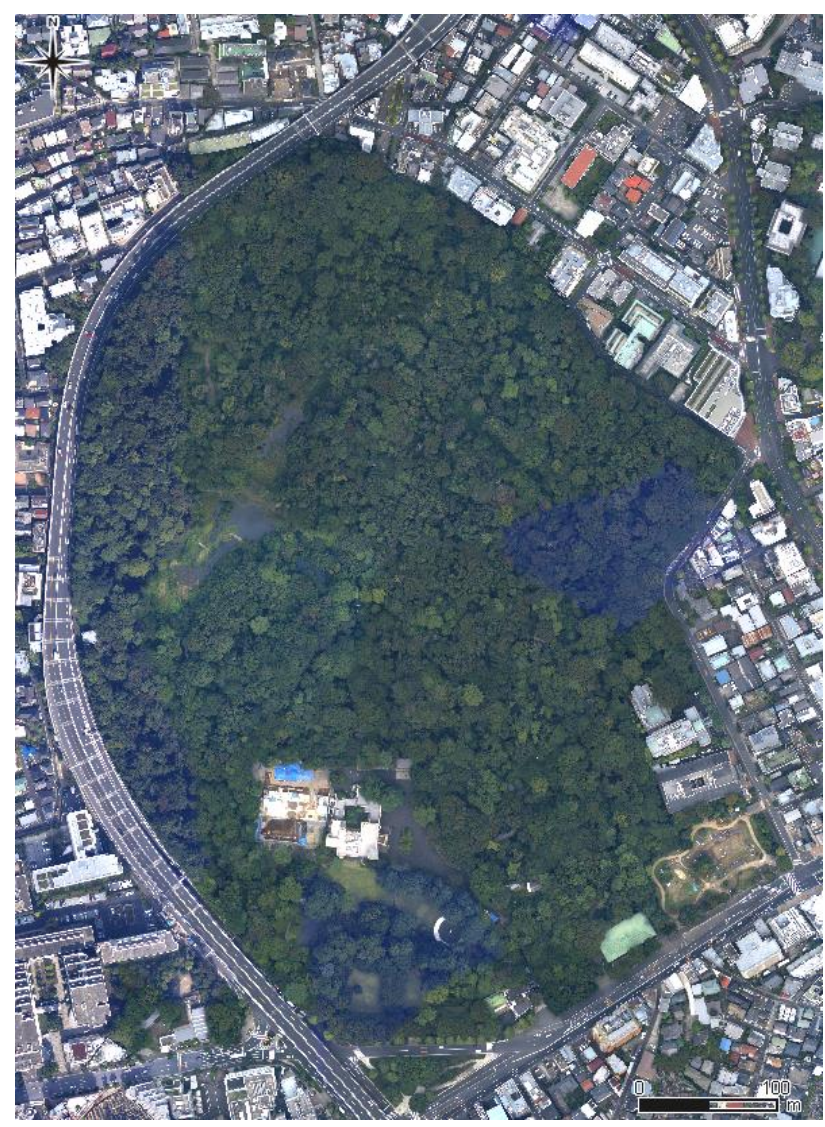

Figure 2. Ortho-image

\begin{tabular}{|l|l|l|}
\hline Domain & Item & Contents \\
\hline \hline Data acquisition & Date & October 20, 2012 \\
\hline Platform & Helicopter & AS-350BA \\
\hline \multirow{2}{*}{ Flight } & Speed & $120 \mathrm{~km} / \mathrm{h}$ \\
\cline { 2 - 3 } & Altitude & $950 \mathrm{~m}$ \\
\hline \multirow{5}{*}{ Laser } & Model & ALTM Orion M300 \\
\cline { 2 - 3 } & Scan rate & $100 \mathrm{kHz}$ \\
\cline { 2 - 3 } & Scan angle & 30 degree (full) \\
\cline { 2 - 3 } & $\begin{array}{l}\text { Number of sample } \\
\text { of waveform }\end{array}$ & 288 \\
\cline { 2 - 3 } & $\begin{array}{l}\text { Waveform } \\
\text { digitization }\end{array}$ & 10 bits \\
\cline { 2 - 3 } & Planned density & 4 points $/ \mathrm{m}^{2}$ \\
\hline Digital Camera & Focal length & $60 \mathrm{~mm}$ \\
\cline { 2 - 3 } & Sensor size & $9 \times 9 \mu \mathrm{m}$ \\
\cline { 2 - 3 } & Image size & $5440 \times 4080$ \\
\cline { 2 - 3 } & Colour band & $\mathrm{R}, \mathrm{G}, \mathrm{B}, \mathrm{IR}$ \\
\hline
\end{tabular}

Table 1. Data specifications

\section{DATA INTERPRETATION}

We extracted samples from the field in order to develop an analysis method for understanding the characteristics of the fullwaveform ALS.

\subsection{Riverside vegetation}

Thick reeds become an issue in ground surface extraction in river areas. Therefore, their waveform was confirmed by extracting data of reeds distributed behind a wetland in the institute, as shown in Figure 3. Figure 4 shows the waveform of the reeds. In the figure, the horizontal axis is the time in nanoseconds, and the vertical axis represents digital value of the reflection intensity. Digital values of the reflection intensity can be converted into Volts using the digitizer offset value and digitizer gain value. The digital values were not converted in this study because the characteristics of the waveform remain unchanged even after unit conversion. Two peaks can be identified in the figure; the first peak is considered to be the top of the reed and the next peak is the ground surface. Since the three-dimensional coordinates of the two peaks are generated using the manufacturer's analysis software, special procedures are not required.

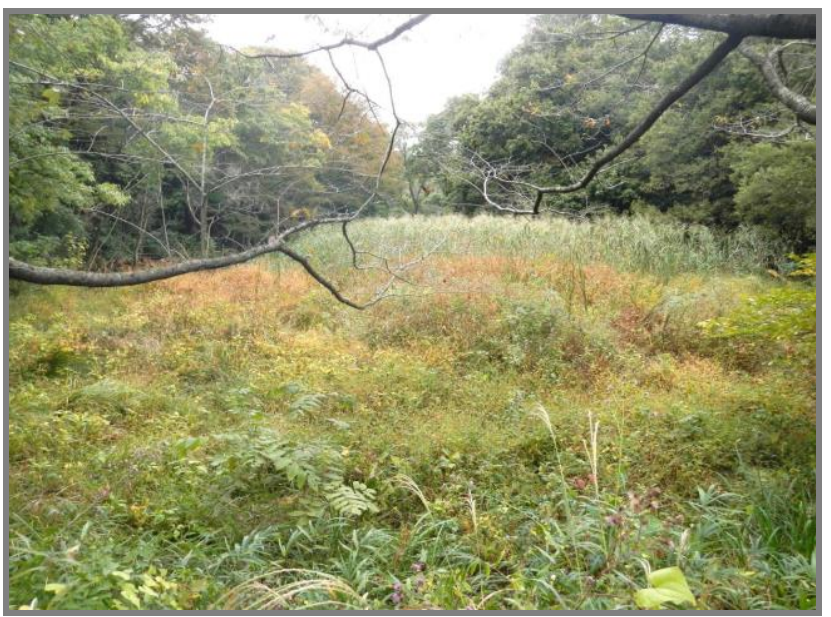

Figure 3. Wetland situation 


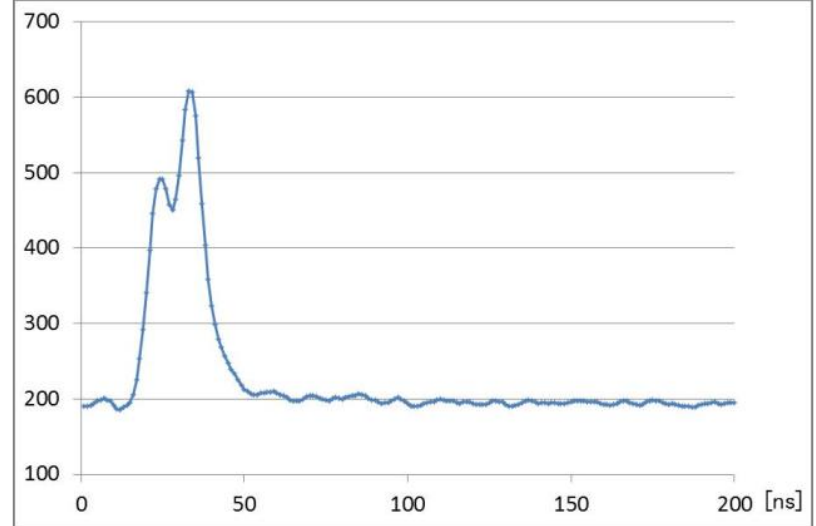

Figure 4. Waveform of reeds

\subsection{Evergreen broad-leaved trees}

Laser beam reaching the ground surface is significantly reduced because they are blocked by leaves and branches in areas with thick evergreen broad-leaved trees. We considered waveform information of Sudajii (Castanopsis sieboldii) as the target, as shown in the right center of Figure 5. Figure 6 shows the three peaks of beams that passed through small gaps of leaves and branches of Sudajii. The three points were generated using the manufacturer's analysis software, and the point of last pulse in the three points is the one that reached the ground surface. However, many of the laser beam reflections from Sudajii were configured as a single peak; this is confirmed by the waveforms in Figure 7 and 8.

It is difficult to extract ground surface when all reflections are concentrated in one crown of Sudajii, as shown in Figure 7. Several minor peaks occur after the major peak shown in Figure 8 . The peak noise at $128 \mathrm{~ns}$ is likely from the ground surface. Classification of valid ground information from one irradiation is difficult, and the ground surface is obtained by analyzing a single pulse based on clear reflection information of the ground, as shown in Figure 7.

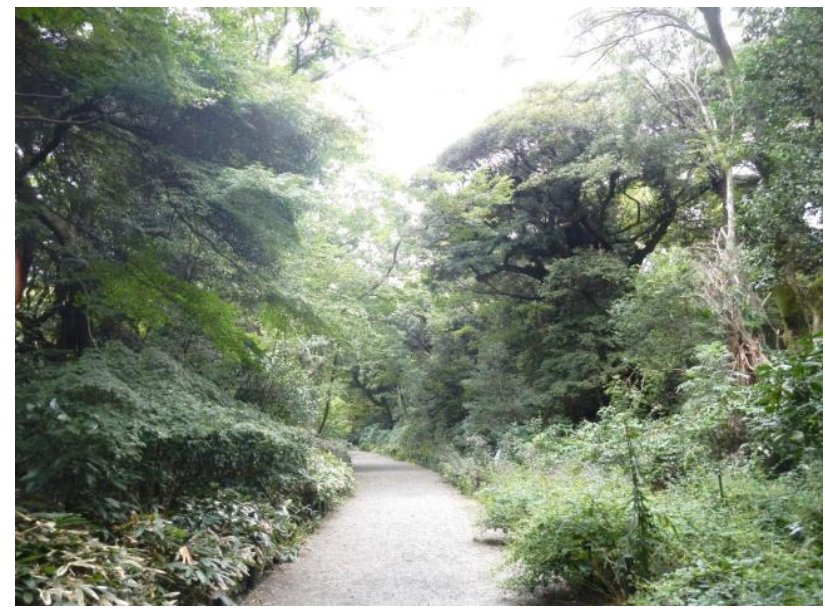

Figure 5. Figure placement and numbering

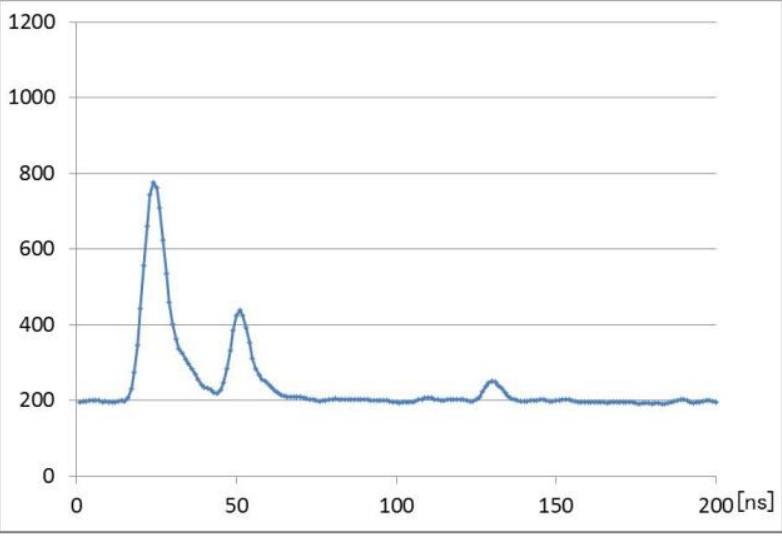

Figure 6. Waveform of Sudajii (three points)

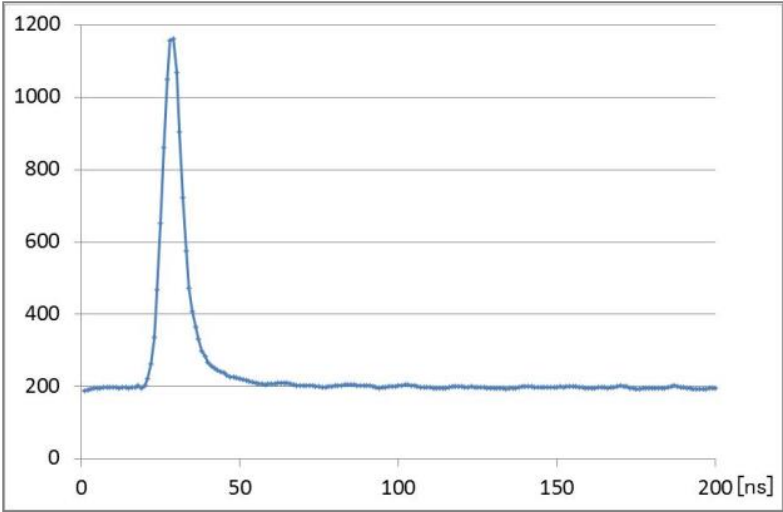

Figure 7. Waveform of Sudajii (single points)

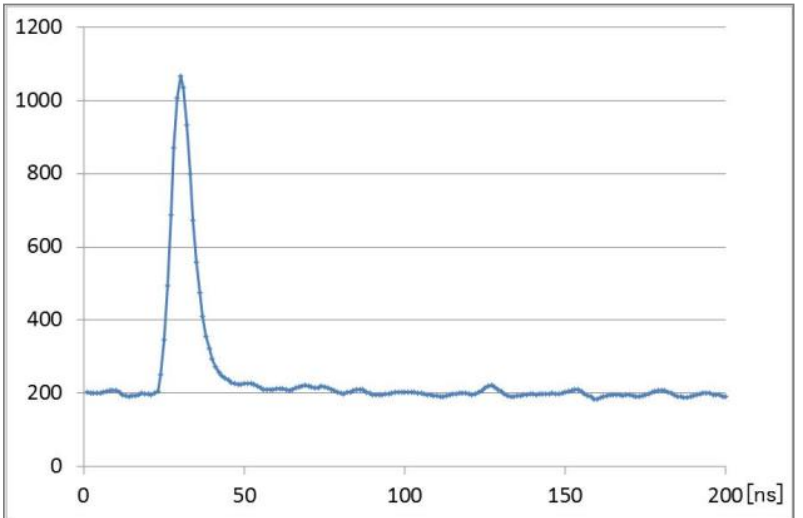

Figure 8. Waveform of Sudajii (single points with noise)

\section{PROPOSED METHOD}

We examined the waveform analysis method based on spatial distribution considering the possibility of ground surface extraction in evergreen broad-leaved trees. The proposed method aims to improve the acquisition rate and the accuracy of ground surface. An airborne laser survey was conducted using grid interpolation to compute three-dimensional coordinates of ground surface in difficult areas such as the area with Sudajii. Figure 9 shows a flowchart of the processes involved in the proposed method. First, a three-dimensional point cloud with waveform information is generated by integrating the 
GNSS/IMU and distance information using the manufacturer's analysis software. Then, a virtual ground surface, giving priority to the lowest point from the three-dimensional point cloud, is generated. Three-dimensional point clouds generated during the waveform analysis are extracted as peaks, assuming waveform as normal distribution, using the Expectation Maximization (EM) algorithm (Dempster, et al., 1977), which was frequently used in previous studies (Persson et al., 2005, Chhatkuli et al., 2012). Finally, ground-surface candidate points are computed using the reflection information and the virtual ground surface. Point cloud data are managed in units of flight course to maintain a close relationship with flight trajectory of the platform. Japanese survey regulations specify a standard flight course sidelap of $30 \%$ lap for ALSs. However, we adopted a $50 \%$ lap by in-house standards, and adjacent courses are able to supplement the entire area for a course. Therefore, a single course has the potential for laser irradiation to reach the ground by passing through different paths of adjacent courses. Point cloud from adjacent courses was used for generating virtual ground surface.

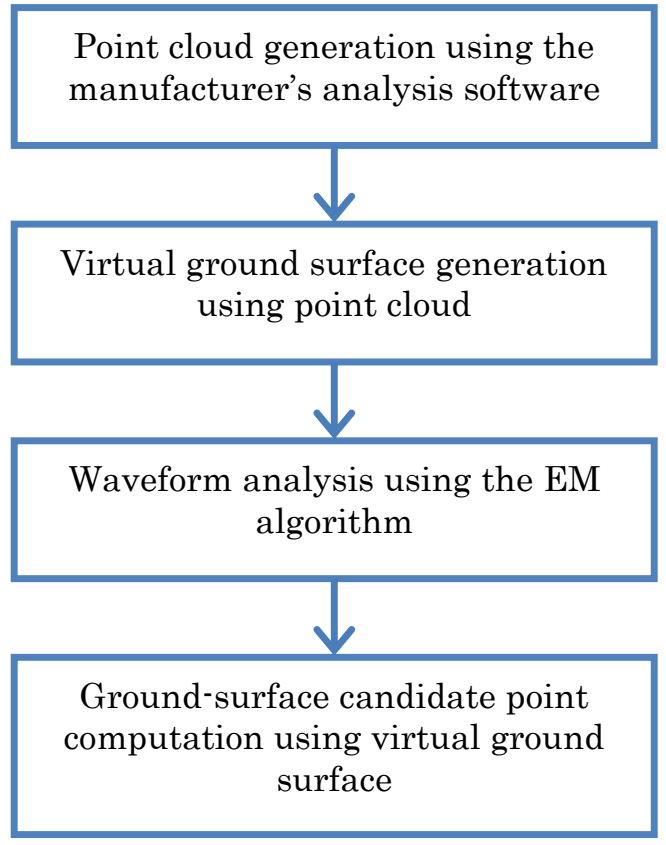

Figure 9. Flawchart of the proposed method

\section{EVALUATION}

The ground-surface candidate points were evaluated by referring to the measured results of the total station. Reference data were observed before the Great East Japan Earthquake. Tokyo area was moved by approximately $29 \mathrm{~cm}$ to the east and it subsided by approximately $3 \mathrm{~cm}$. However, elevation data were obtained directly from the results because accurate parameters for elevations could not be obtained from the Geospatial Information Authority of Japan.

The proposed method was verified on a selected test area $(40 \mathrm{~m}$ $\times 40 \mathrm{~m}$ ) at the Institute for Nature Study as shown in Figure 2 . The test area comprises a dense community of mainly Sudajii, and includes 10 checkpoints.

Figure 10 shows the virtual ground surface from a single course, and Figure 11 shows the virtual ground surface including the adjacent course.
A virtual ground surface of $2.5 \mathrm{~m}$ grid spacing was created using the low point priority of point cloud; in addition, a virtual ground surface of $20 \mathrm{~m}$ grid spacing was created using $2.5 \mathrm{~m}$ grid spacing. Spike noises in virtual ground surface from the single course are confirmed, as shown in Figure 10. In contrast, spike noises are reduced in virtual ground surface using adjacent courses.

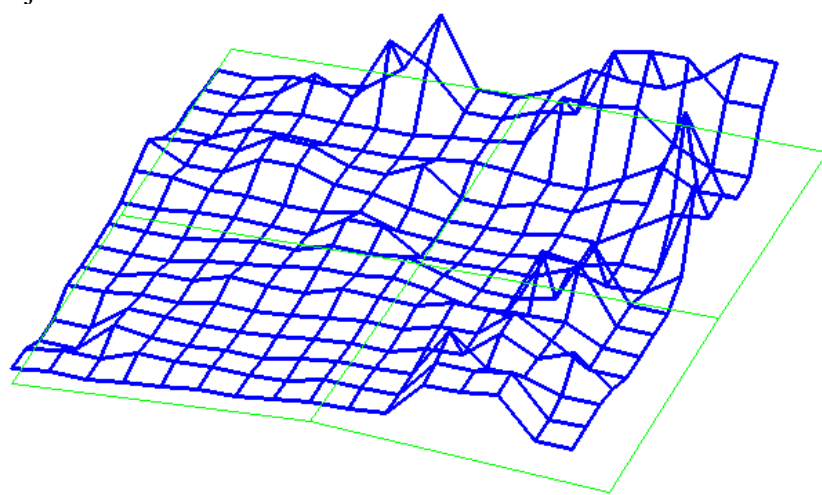

Figure 10. Virtual ground surface from a single course

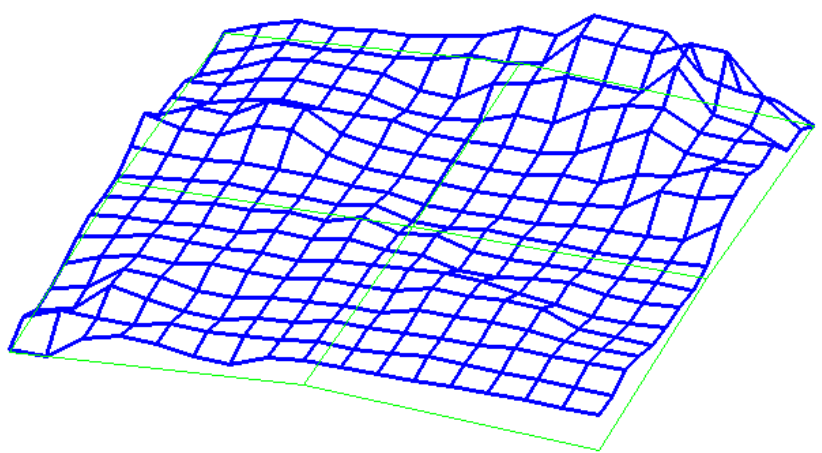

Figure 11. Virtual ground surface including the adjacent course

The accuracy of this method was evaluated from checkpoints for ground-surface candidate points computed using the virtual ground surface of the single and adjacent courses.

Table 2 shows RMS error for 10 checkpoints, which were computed using checkpoint height and interpolated height under the inverse distance weighted method using the horizontal position of checkpoint and ground surface candidate point coordinates.

The effect of the adjacent courses is confirmed by the fact that RMS error is reduced from $2.4 \mathrm{~m}$ to $0.6 \mathrm{~m}$ as shown in Table 2 . As a reference, it shows the RMS error calculated from the lowest elevation in the range of $1 \mathrm{~m}$ around the checkpoints using the last pulse, which has been calculated using the manufacturer's analysis software. The test area consists of thick trees, and the RMS error of the last pulse is greater than eight meters.

\begin{tabular}{|l|c|}
\hline \multicolumn{1}{|c|}{ Case of computation } & RMS error \\
\hline $\begin{array}{l}\text { Ground-surface candidate points using } \\
\text { single course }\end{array}$ & $\pm 2.445 \mathrm{~m}$ \\
\hline $\begin{array}{l}\text { Ground-surface candidate points using } \\
\text { including adjacent courses }\end{array}$ & $\pm 0.604 \mathrm{~m}$ \\
\hline $\begin{array}{l}\text { Last pulse points from discrete point } \\
\text { cloud }\end{array}$ & $\pm 8.365 \mathrm{~m}$ \\
\hline
\end{tabular}

Table 2. RMS error for 10 checkpoints 


\section{CONCLUSION}

A fundamental study on ground surface extraction for CIM was conducted using a full-waveform ALS. The proposed method was analyzed with weak reflection information from the ALS considering spatial distribution using virtual ground surface. The proposed method was able to improve the accuracy of the ground candidate points and virtual ground surface using point cloud of adjacent courses in the test area with thick evergreen broad-leaved trees such as Sudajii.

It can be concluded that the proposed method is useful for ground surface extraction in heavily forested areas, where it cannot be extracted by discrete ALSs.

However, there are several issues in that the accuracy of ground-surface candidate points is influenced by the virtual ground surface, and difficulties arise when all reflections are concentrated on only the crown of trees, as shown in Figure 7.

\section{ACKNOWLEDGEMENTS}

Checkpoint data were obtained with the cooperation of the Institute for Nature Study. We would like to express our gratitude to this institute.

\section{REFERENCES}

Dempster A, Laird N, Rubin D, 1977. Maximum likelihood from incomplete data via the EM algorithm. J Roy Stat Soc Series B, 39, pp.1-38.

Persson, Å., Söderman, U., Töpel, J., Alhberg, S., 2005. Visualization and analysis of full-waveform airborne laser scanner data. International Archives of Photogrammetry, Remote Sensing and Spatial Information Sciences 36 (Part3/W19), 103108

Chhatkuli S, Mano K, Kogure T, Tachibana K, and Shimamura H, 2012. Full Waveform LIDAR Exploitation Technique and Its Evaluation in the Mixed Forest Hilly Region, Int. Arch. Photogramm. Remote Sens. Spatial Inf. Sci., XXXIX-B7, pp.505-509. 